\title{
The Influence of Acute, Subacute and Chronic Intoxication of Sodium Meta-Arsenite on Innate Immunity and Integral State of Innate and Adaptive Immunity System
}

\author{
Pavel Franzevich Zabrodskii* \\ Saratov Medical University "REAVIZ", Saratov, Russia \\ *Corresponding Author: Pavel Franzevich Zabrodskii, Saratov Medical University "REAVIZ", Saratov, Russia.
}

Received: October 5, 2019; Published: October 24, 2019

DOI: 10.31080/ASMI.2019.02.0409

\begin{abstract}
Experiments on random-bred albino mice and rats showed that acute (0.1-0.8 $\left.\mathrm{LD}_{50}\right)$, subacute $\left(1 / 7 \mathrm{LD}_{50}, 6\right.$ days) and chronic intoxication $\left(0.01 \mathrm{LD}_{50}, 30\right.$ days) of sodium meta-arsenite (SMA) causes a dose-dependent reduction of the anti-infection nonspecific resistance (innate immunity), which is manifested by the increase of mortality of mice from experimental peritonitis caused by $E$. coli, reduction of $\mathrm{LD}_{50}$ E. coli and average effective life of animals $\left(\mathrm{Et}_{50}\right)$. SMA acute, subacute and chronic intoxication significantly reduced the integral state of the innate and adaptive immunity system - anti-infection nonspecific and immunological resistance (increase of mortality of rats from experimental pneumonia, decrease of $\mathrm{LD}_{50}$ P. vulgaris and $\mathrm{Et}_{50}$, when using P. vulgaris after preliminary immunization by $10^{6}$ CFUs diurnal culture P. vulgaris).
\end{abstract}

Keywords: Sodium Meta-Arsenite; Innate Immunity; Adaptive Immunity; E. coli; P. vulgaris; Sepsis

\section{Introduction}

The immune system of humans and animals in ecologically unfavorable areas is under double pressure, both as a result of the direct action of contaminants and as a result of the increasing persistent potential of microorganisms that violate the preimmune and immune mechanisms of protection against infections. As a result, the probability of damage to the congenital and adaptive immunity system, the emergence of secondary immunopathological conditions and the resulting infectious complications and diseases increases significantly [1-4].

According to the World Health Organization (WHO) and the Agency for Toxic Substances and Disease Registry arsenic is the number one contaminant of concern for human health worldwide. Hundreds of millions of people worldwide are exposed to arsenic via their drinking water, many at doses higher than the WHO maximum contaminant level of $10 \mathrm{ppb}$ [5-7].

The United Nations Conference in Rio de Janeiro in 1992 showed that the environment and socio-economic development can no longer be considered as isolated areas of activity. Therefore, the adopted Agenda 21 program defines the ways of global cooperation for the purpose of harmonious achievement of high quality environment and healthy economy for all peoples of the world. One of the objectives of the programme is to stop and prohibit the use of high-risk chemicals, which are toxic and persistent [4].

Arsenic is the number one contaminant of concern with regard to human health according to the World Health Organization. Epidemiological studies on Asian and South American populations have linked arsenic exposure with an increased incidence of lung disease, including pneumonia, and chronic obstructive pulmonary disease, both of which are associated with bacterial infection. However, little is known about the effects of low dose arsenic exposure, or the contributions of organic arsenic to the innate immune response to bacterial infection [8]. Chronic arsenic poisoning is recognized as an important global public health issue, as prolonged exposure to inorganic arsenic, in particular sodium meta-arsenite (SMA), reduces congenital and adaptive immunity and stimulates carcinogenesis [4,9-11]. 
The Influence of Acute, Subacute and Chronic Intoxication of Sodium Meta-Arsenite on Innate Immunity and Integral State of Innate and Adaptive Immunity System

\section{Aim of the study}

Analyze the effect of sodium meta-arsenite on innate immunity (E. coli, sepsis) and the integral state of the innate and adaptive immunity system (anti-infection nonspecific and immunological resistance of the organism) after immunization of $P$. vulgaris.

\section{Materials and Methods}

The experiments were performed on random-bred albino rats and mice of both sexes weighing 180-240 $\mathrm{g}$ and 18-22 $\mathrm{g}$ respectively. Experiments on animals were conducted in accordance with the requirements of the Geneva Convention "International Guiding Principles for Biomedical Research Inroling Animals" (Geneva, 1990). SMA (Sigma-Aldrich) was administered subcutaneously in doses of 0.1-0.8 $\mathrm{LD}_{50}\left(\mathrm{LD}_{50}\right.$ SMA for mice and rats was $40.2 \pm 2.0$ and $47.1 \pm 2.2 \mathrm{mg} / \mathrm{kg}$, respectively). Subacute action was simulated by administration of SMA for 6 days in a single dose of $1 / 7 \mathrm{LD}_{50}$, and chronic - in a single dose of $0.01 \mathrm{LD}_{50}$ for 30 days.

The control groups (SMA acute intoxication) of mice received i.p. $1.3-2.0 \mathrm{ml}$ isotonic sodium chloride solution (saline) at $24 \mathrm{~h}$ after subcutaneous injection saline $(0.5 \mathrm{ml})$. In the control groups (SMA subacute and chronic intoxication) saline $(0.5 \mathrm{ml})$ was injected a single dose (daily) for 6 and 30 days, respectively.

The study of the integral state of the organism's anti-infection nonspecific resistance (innate immunity) was determined by the indices of the experimental infection course caused by intraperitoneal injection of mice of the E. coli daily culture suspension in a single doses of $1.5 \times 10^{9}, 2.0 \times 10^{9}$ and $2.5 \times 10^{9} \mathrm{CFUs}$ diurnal culture of E. coli 0157:H7 in 1.3-2.0 ml of saline (sepsis modeling) without preliminary immunization [4,12-14].

Anti-infection nonspecific resistance (innate immunity) and the integral state of the innate and adaptive immunity system (anti-infection nonspecific and immunological resistance of the organism) was evaluated by mortality of mice (E. coli, i.p.) and rats ( $P . v u l-$ garis, into lung tissue) during 36 and $48 \mathrm{~h}$ from experimental infection (sepsis modeling), as well as by mean lethal doses $\left(\mathrm{LD}_{50}\right)$ of E. coli and P. vulgaris and mean effective lifetime of animals $\left(\mathrm{Et}_{50}\right)$ in experimental and control groups calculated by probit analysis [12]. Introduction of E. coli and P. vulgaris was performed $24 \mathrm{~h}$ after SMA acute intoxication and 6 days after SMA subacute intoxication. In SMA chronic intoxication, immunization of $P$. vulgaris was performed for 25 days.
The integral state of the innate and adaptive immunity system (anti-infection nonspecific and immunological resistance of the organism) in the action of SMA was determined by the indices of the experimental infection course caused by the intra-pulmonary introduction of $P$. vulgaris diurnal culture (suspension) to rats. $P$. vulgaris in doses of $4.0 \times 10^{9}, 6.0 \times 10^{9}$ и $12.0 \times 10^{9}$ CFUs diurnal culture in the amount of 3-6 ml saline after 4 days pre-infused dose - immunization- of $10^{6} \mathrm{CFUs}$ diurnal culture in the volume of 0.5 $\mathrm{ml}$ saline.

The data obtained were processed statistically using the Student's t-test. Differences between the parameters were considered reliable at $\mathrm{p}<0.05$.

\section{Results}

Acute SMA intoxication resulted in a dose-dependent increase in mice' mortality from experimental infection. At the same time, $\mathrm{LD}_{50}$ E. coli and average effective life time of animals - $\mathrm{Et}_{50}-$ were quite naturally reduced. So, at action SMA in doses $0.1,0.2,0.5,0.8$ $\mathrm{LD}_{50}$ E. coli $\mathrm{LD}_{50}$ decreased accordingly in 1.35 ( $\mathrm{p}>0.05$ ), 1.58, 1.63 and 1.69 times $(\mathrm{p}<0.05)$ (Table 1$)$, and $\mathrm{Et}_{50}-1.46,1.61,1.92$ and 2.11 times, respectively $(\mathrm{p}<0.05)$. At $0.1,0.2,0.5,0.8 \mathrm{LD}_{50}$ doses of SMA compared with control, where the mortality rate of mice was $55.7+5.9 \%$, this indicator increased in 2.2 ( $p>0.05$ ), 18.0, 30.9, and $25.6 \%(\mathrm{p}<0.05)$, respectively.

\begin{tabular}{|l|c|c|}
\hline Dose of SMA, $\mathbf{L D}_{\mathbf{5 0}}$ & $\mathbf{L D}_{\mathbf{5 0}} \mathbf{E}$. coli, 10 $\mathbf{~} \mathbf{C F U s}$ & $\mathbf{E t}_{\mathbf{5 0}, \mathbf{h}}$ \\
\hline Control & $1.91 \pm 0.16(70)$ & $19.0 \pm 1.3(7)$ \\
\hline 0.1 & $1.42 \pm 0.25(19)$ & $13.0 \pm 2.0(19)$ \\
\hline 0.2 & $1.21 \pm 0.17^{*}(19)$ & $11.8 \pm 1.6^{*}(19)$ \\
\hline 0.5 & $1.17 \pm 0.25^{*}(16)$ & $9.9 \pm 1.5^{*}(16)$ \\
\hline 0.8 & $1.13 \pm 0.25^{*}(15)$ & $9.0 \pm 1.3^{*}(15)$ \\
\hline
\end{tabular}

Table 1: The effect of SMA acute intoxication on anti-infection nonspecific resistance (innate immunity) $\left(\mathrm{LD}_{50}\right.$ E. coli-i.p.- and $\mathrm{Et}_{50}$ in mice without immunization) $(\mathrm{M} \pm \mathrm{m})$

* - p $<0.05$ compared with control; in parentheses is the number of mice.

In subacute (1/7 LD50 for 6 days) and chronic SMA intoxication, rat mortality increased compared to control by 24.9 and $49.9 \%$ respectively $(\mathrm{p}<0.05)$. In these SMA exposures (subacute and chronic SMA intoxication), $\mathrm{LD}_{50}$ E. coli and $\mathrm{Et}_{50}(\mathrm{p}<0.05)$ decreased significantly (Table 2). 
The Influence of Acute, Subacute and Chronic Intoxication of Sodium Meta-Arsenite on Innate Immunity and Integral State of Innate and Adaptive Immunity System

\begin{tabular}{|l|c|c|}
\hline $\begin{array}{l}\text { Doses; } \\
\text { expositions, day }\end{array}$ & $\begin{array}{c}\mathbf{L D}_{\mathbf{5 0}} \mathbf{E . c o l i}, \mathbf{1 0}^{\mathbf{9}} \\
\text { CFUs }\end{array}$ & $\mathbf{E t}_{\mathbf{5 0},} \mathbf{h}$ \\
\hline Control & $10.1 \pm 1.0(32)$ & $40.0 \pm 4.1(32)$ \\
\hline $1 / 7 \mathrm{LD}_{50} \times \mathbf{6}$ & $6.0 \pm 0.7^{*}(16)$ & $23.9 \pm 2.5^{*}(16)$ \\
\hline $0.01 \mathrm{LD}_{50} \times \mathbf{3 0}$ & $5.4 \pm 0.6^{*}(16)$ & $22.1 \pm 2 / 4^{*}(16)$ \\
\hline
\end{tabular}

Table 2: The effect of SMA subacute and chronic intoxication on anti-infection nonspecific resistance (innate immunity) $\left(\mathrm{LD}_{50} E\right.$. coli -i.p.- and $\mathrm{Et}_{50}$ in mice without immunization) $(\mathrm{M} \pm \mathrm{m})$

* $-\mathrm{p}<0.05$ compared with control; in parentheses is the number of mice.

Thus, after acute, subacute and chronic intoxication of SMA there is a dose-dependent increase in the mortality of animals from experimental peritonitis caused by $E$. coli, as well as a decrease in $\mathrm{LD}_{50}$ E. coli and the average effective life time of animals $\left(\mathrm{Et}_{50}\right)$, which indicates a decrease in anti-infection nonspecific resistance (innate immunity) under the influence of SMA.

In the evaluation of the integral state of the innate and adaptive immunity system (anti-infection nonspecific and immunological resistance of the organism) after SMA acute intoxication it was established that SMA in doses of $0.1,0.2,0.5,0.8 \mathrm{LD}_{50}$ leads to a dosedependent increase in the mortality of rats from experimental pneumonia (immunization, $10^{6} \mathrm{CFUs}$ diurnal culture P. vulgaris).

So, at doses of SMA, making $0.1,0.2,0.5,0.8 \mathrm{LD}_{50}$, in comparison with the control at which mortality made $28.9+5.6 \%$ this indicator increased accordingly by 8.9 ( $p>0.05$ ), 14.4, 28.4 and $51.2 \%$ $(p<0.05)$. The increase in the mortality of animals from experimental infection is associated with a decrease in $\mathrm{LD}_{50}$ P. vulgaris and $\mathrm{Et}_{50}$. Thus, at the action of SMA in doses of 0.1, 0.2, 0.5, $0.8 \mathrm{LD}_{50}$ P. vulgaris decreased in 1.23 ( $\mathrm{p}>0.05), 1.60,1.80$ and 1.90 times $(\mathrm{p}<0.05)$, and $\mathrm{Et}_{50}$ - in 1.21 ( $\left.\mathrm{p}>0.05\right), 1.31,1.40$ and 1.74 times $(\mathrm{p}<0.05)$, respectively (Table 3$)$.

\begin{tabular}{|l|c|c|}
\hline $\begin{array}{l}\text { Dose of } \\
\text { SMA, } \mathbf{L D}_{\mathbf{5 0}}\end{array}$ & $\mathbf{L D}_{\mathbf{5 0}}$ P.vulgaris, 10 $\mathbf{~}^{\mathbf{C F U}}$ & $\mathbf{E t}_{\mathbf{5 0 , \mathbf { h }}}$ \\
\hline Control & $11.2 \pm 1.1(32)$ & $48.5 \pm 4.6(32)$ \\
\hline 0.1 & $9.1 \pm 1.3(18)$ & $40.1 \pm 3.1(18)$ \\
\hline 0.2 & $7.0 \pm 1.1^{*}(18)$ & $37.0 \pm 2.5^{*}(18)$ \\
\hline 0.5 & $6.2 \pm 0.9^{*}(18)$ & $34.7 \pm 2.3^{*}(18)$ \\
\hline 0.8 & $5.9 \pm 0.8^{*}(19)$ & $27.9 \pm 2.2^{*}(19)$ \\
\hline
\end{tabular}

Table 3: The effect of SMA acute intoxication on the integral state of the innate and adaptive immunity system (anti-infection nonspecific and immunological resistance of the organism) $\left(\mathrm{LD}_{50}\right.$ P.vulgaris - into lung tissue- and $\mathrm{Et}_{50}$ in rats, immunization) (M \pm $\mathrm{m})$.

* -p $<0.05$ compared with control; in parentheses is the number of rats.
In case of SMA subacute and chronic intoxication, the mortality of rats increased by 37.4 and $41.1 \%$, respectively, in comparison with the control $(\mathrm{p}<0.05$; control $-28.4 \pm 5.2 \%)$. At the given exposures of SMA significantly decreased $\mathrm{LD}_{50}$ P. vulgaris and $\mathrm{Et}_{50}$ $(\mathrm{p}<0.05)$. Thus, at SMA subacute and chronic intoxication $\mathrm{LD}_{50} P$. vulgaris decreased in 1.49 and 1.66 times $(\mathrm{p}<0.05)$, respectively, and $\mathrm{Et}_{50}$ in 1.73 and 1.62 times ( $\mathrm{p}<0.05$ ), respectively (Table 4). Significant differences of the studied parameters at s SMA subacute and chronic intoxication were not revealed at the studied doses and expositions.

\begin{tabular}{|l|c|c|}
\hline $\begin{array}{l}\text { Doses; } \\
\text { expositions, day }\end{array}$ & $\begin{array}{c}\mathbf{L D}_{\mathbf{5 0}} \text { P.vulgaris, 10 } \\
\text { CFUs }\end{array}$ & Et $_{\mathbf{5 0}} \mathbf{h}$ \\
\hline CONTROL & $11.2 \pm 1.1(32)$ & $48.5 \pm 4.6(32)$ \\
\hline $1 / 7 \mathrm{LD}_{50} \times 6$ & $6.8 \pm 0.8^{*}(16)$ & $28.0 \pm 3.3^{*}(16)$ \\
\hline $0.01 \mathrm{LD}_{50} \times 30$ & $6.1 \pm 0.6^{*}(15)$ & $30.0 \pm 3.1^{*}(15)$ \\
\hline
\end{tabular}

Table 4: The effect of SMA subacute and chronic intoxication on the integral state of the innate and adaptive immunity system (antiinfection nonspecific and immunological resistance of the organism) $\left(\mathrm{LD}_{50} E\right.$. coli - into lung tissue- and $\mathrm{Et}_{50}$ in rats, immunization) $(\mathrm{M} \pm \mathrm{m})$.

* -p $<0.05$ compared with control; in parentheses is the number of rats.

\section{Discussion}

The reduction of the organism's anti-infection nonspecific resistance (innate immunity) and the integral state of the innate and adaptive immunity system (anti-infection nonspecific and immunological resistance of the organism) after SMA intoxication the may be caused by the interaction of the SMA with dehydrolipoic acid of the pyruvatoxidase system of macrophage cells, monocytes, NK and other blood cells - inhibition of mono- and dithiolic enzymes (the toxicant - SMA- itself or its metabolites) [1-4,10,12,13,15]. The revealed changes in innate immunity parameters under the influence of SMA may also be caused by the inhibition of $\mathrm{T}$ lymphocyte, NK and other immune system cells acetylcholinesterase, the reduction of innate immunity primers is caused by a decrease in tissue respiration processes and a decrease in oxidative phosphorylation, inhibition of some enzymes, e.g. esterases of cellular elements [1-4]. At the same time, in addition to reducing the production of non-specific factors of organism protection, resistance of tissue cells to microorganisms and their toxins is probably reduced [1-4]. It is possible that in addition to the inhibition reduction of ATP formation from ADP (oxidation and phosphorylation dissociation), monoaminoxidase, alanine aminotransferase, aspartate aminotransferase, reduction of coenzyme A function, violation of the tricarboxylic acid cycle, blocking of DNA polymerase $[1-4,10,15]$ in leukocytes that provide the integral state of the organism's anti-in- 
The Influence of Acute, Subacute and Chronic Intoxication of Sodium Meta-Arsenite on Innate Immunity and Integral State of Innate and Adaptive Immunity System

fection nonspecific resistance (of various cells in the body), which leads to a decrease in their resistance to the development of peritoneal inflammation and sepsis.

The decrease of the integral state of the innate and adaptive immunity system (anti-infection nonspecific and immunological resistance) under the influence of SMA may also be related to the inhibition by the toxicant succinate-Q oxidoreductase [FAD (FADH2) and others], reduced and oxidized ubiquinone and cytochrome b245 leukocytes. Other mechanisms of disturbed NADH-coenzyme $\mathrm{Q}$ oxidoreductase of neutrophil functioning are also possible. Probably, SMA, except for oxygen-dependent anti-infection systems of phagocytosis, also affect oxygen-independent microbicidal systems of phagocytes [1-4,10].

\section{Conclusion}

Acute (0.1-0.8 $\left.\mathrm{LD}_{50}\right)$, subacute $\left(1 / 7 \mathrm{LD}_{50}, 6\right.$ days) and chronic intoxication ( $0.01 \mathrm{LD}_{50}, 30$ days) of sodium meta-arsenite causes a dose-dependent reduction of the anti-infection nonspecific resistance (innate immunity), which is manifested by the increase of mortality of mice from experimental peritonitis caused by E. coli, reduction of $\mathrm{LD}_{50}$ E. coli and average effective life of animals $\left(\mathrm{Et}_{50}\right)$. SMA acute, subacute and chronic intoxication significantly reduced the integral state of the innate and adaptive immunity system - anti-infection nonspecific and immunological resistance (increase of mortality of rats from experimental pneumonia, decrease of $\mathrm{LD}_{50} P$. vulgaris and $\mathrm{Et}_{50}$, when using $P$. vulgaris after preliminary immunization by $10^{6}$ CFUs diurnal culture $P$. vulgaris).

\section{Bibliography}

1. Zabrodskii PF and Mandych VG. "Immunotoxicology of xenobiotics". Saratov Military Institute of Biological and Chemical Safety (2007): 420.

2. PF Zabrodskii. "Immunotropic properties of poisons and drugs". Saratov. Saratov State Medical University (1998): 213.

3. PF. Zabrodskii. "Influence of xenobiotics on immune homeostasis". In: General toxicology. Ed. BA Kurlyandsky, VA Filov. Moscow. Medicine (2002):352-384.

4. Zabrodskii PF. "Variation in antiinfectious nonspecific resistance of the organism caused by cholinergic stimulation". Bulletin of Experimental Biology and Medicine 120.2 (1995): 809-811.
5. Mandal BK and Suzuki KT. "Arsenic round the world: a review". Talanta 58.1 (2002): 201-235.

6. Li J., et al. "Imbalanced immune responses involving inflammatory molecules and immune-related pathways in the lung of acute and subchronic arsenic-exposed mice". Environmental Research 159 (2017): 381-393.

7. Chung JY., et al. "Environmental source of arsenic exposure". Journal of Preventive Medicine and Public Health 47.5 (2014):253-257.

8. Notch EG., et al. "Monomethylarsonous Acid (MMAIII) Has an Adverse Effect on the Innate Immune Response of Human Bronchial Epithelial Cells to Pseudomonas aeruginosa". PLoS One 10.11 (2015): e0142392.

9. Yu HS., et al. "Arsenic carcinogenesis in the skin". Journal of Biomedical Science 13.5 (2006): 657-866.

10. Zabrodskir PF., et al. "The effect of unithiol on the changes in immunotoxicity of 2 - chloroethenyl chloro arsine". Eksperimental'naia i klinicheskaia farmakologiia (2002): 5355.

11. Palmieri MA., et al. "Evaluation of metabolic reactivity in macrophages from mice with chronic sodium arsenite intake and experimental carcinogenesis". Cellular and molecular biology (Noisy-le-Grand) 64.10 (2018): 34-39.

12. Zabrodskii PF. "Effect of armin on nonspecific resistance factors of the body and on the primary humoral immune response". Farmakologiia I Toksikologiia 50.1 (1987): 57-60.

13. Zabrodskii PF. "Change in the non-specific anti-infection resistance of the body exposed to cholinergic stimulation". Bulletin of Experimental Biology and Medicine 120.8 (1995): 164-166.

14. Song DJ., et al. "Effect of lentiviral vector encoding on triggering receptor expressed on myeloid cells 1 on expression of inflammatory cytokine in septic mice infected by Bacteroides fragilis". Zhonghua Shao Shang Za Zhi. 25.1 (2009): 36-41.

15. Male D., et al. "Immunology, 7th E"'. Elsevier (2006): 563.

\section{Volume 2 Issue 11 November 2019 (c) All rights are reserved by Pavel Franzevich Zabrodskii.}

